\title{
Creativity unleashed
}

\author{
Hands-on challenges such as building a low-cost atomic force microscope for schools can teach more \\ than standard lessons, says François Grey.
}

W hen I arrived as a visiting professor at Tsinghua University in 2008, one of my first tasks was to set up an international summer school that would expose foreign students to the many exciting advances being made in China in the field of nanotechnology, and to encourage them to collaborate with their Chinese counterparts on practical projects. This summer school became an annual fixture, thanks to an ongoing collaboration between the London Centre for Nanotechnology at University College London (UCL), the Centre for Nano and Micro Mechanics at Tsinghua University and the Institute of Micro/Nanoelectronics at Peking University. By experimenting with the format over the years, I realized that hands-on projects, rather than lectures by experts, worked best for this interdisciplinary subject and international mix of students.

In 2013, inspired by the memory of Heinrich Rohrer - co-inventor of the scanning tunnelling microscope - I decided to set the summer school students a seemingly impossible task: build a do-ityourself atomic force microscope (AFM) suitable for use in Chinese schools, for under US\$1,000. I also chose to model the week-long event on software hackathons, events where teams compete to come up with simple solutions, or 'hacks', to a tough challenge. With the help of a grant from the LEGO Foundation, which supports research on hands-on learning by children, I set about planning the LEGO2NANO summer school. Some colleagues were initially sceptical about the radical change of format and outlandish ambition, but several $\mathrm{PhD}$ students and younger faculty from the UK and China enthusiastically pitched in to help. New partners joined the effort, including UCL's Institute of Making and Tsinghua University's eXtreme Learning Process team.

For the school, we selected students from a broad background, including from fields such as industrial design and psychology, and with experience spanning from bachelor to $\mathrm{PhD}$ levels. Local high school and middle school students were invited to participate in different stages of the event, and their many ideas for how to use the AFM in schools proved inspirational. Lectures only occurred during lunch breaks, and had

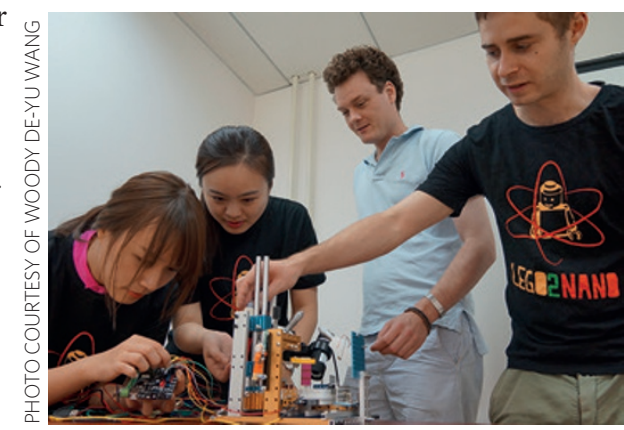

non-traditional themes, including thoughtprovoking introductions to the rapidly emerging maker movement in China, and the global hive of low-cost hardware production in Shenzhen.

In just five days (and several nights for some), the teams came up with a series of clever innovations, which tackled many of the challenges related to making a do-ityourself AFM for schools. The students were highly resourceful, using cheap components bought in the nearby electronics markets of Zhongguancun, Beijing's silicon valley region, as well as custom $3 \mathrm{D}$-printed parts and a good deal of LEGO to assemble their prototypes. At the end of the week, exhausted students raved about what a learning experience the event had been. But what happened next was perhaps even more inspiring. A wave of interest spread around the world, thanks to a slew of articles about the event, first in the Chinese press, and then in Western media. We were inundated with messages from people who had ideas - and sometimes prototypes - for how to make a do-it-yourself AFM.

In fact, we are still some way from a sub-US\$1,000 AFM kit. But a fruitful collaboration with the group of En-Te Hwu at Academia Sinica in Taiwan has resulted in a prototype that Beijing middle school students can assemble and start operating in half a day. Intriguingly, one of the first things that they decided to study with their new tool was the pollution that often fouls the air of China's capital. What they discovered was how PM2.5 - the measure of microscopic pollutants commonly referred to in newspapers and on TV - in fact represents a distribution of particle sizes extending far into the nanoscale range. This prompted discussions about the relative health risks of different size particles, and their possible origins.

At the second LEGO2NANO summer school, held in September last year, new student teams went beyond the hardware design to look at how to bring down the cost of the associated electronics and software for operating the AFM. They even explored possibilities of crowdfunding the production of such devices, and crowdsourcing the analysis of the data that schoolchildren could gather with them.

The extension of LEGO2NANO to broader online public participation, or 'citizen cyberscience' is particularly important, if the project is to scale beyond a few select schools, and have a wider effect on the ongoing reforms to the education system in China. These reforms seek to wean schools off rote learning and an obsession with exam results, and introduce the sort of creative skills that are increasingly important for the Chinese economy.

Inspired in part by the sort of creative potential that LEGO2NANO unleashed, Tsinghua University is launching a major initiative with the LEGO Foundation this year, called the Lifelong Learning Lab. Led by Yingqing Xu of Tsinghua's Academy of Arts and Design, this lab will explore new, hands-on ways to boost creativity in the classroom. Other collaborators in this initiative include the Lifelong Kindergarten group at the Massachusetts Institute of Technology Media Lab, where the first programmable bricks were developed that inspired the hugely popular LEGO Mindstorms robotics kits. In a similar spirit, one of the bold ambitions for the Lifelong Learning Lab is for students of all ages, from preschool to $\mathrm{PhD}$, to collaborate on developing kits that stimulate children's scientific curiosity in playful ways, and connect the building blocks of childhood with those of nature.

FRANCOIS GREY is co-director of the Lifelong Learning Lab at Tsinghua University, 100084 Beijing, China, and coordinator of the Citizen Cyberscience Centre at the University of Geneva, CUI, 7 Route de Drize, 1227 Carouge, Switzerland. e-mail: francois.grey@cern.ch 